\title{
O Papel do Teatro na Escola para o Despertar da Filosofia
}

\author{
Aline Wendpap Nunes de Siqueira* \\ Secretaria de Educação do estado de Mato Grosso - Seduc/MT \\ E-mail: alinewendpap@gmail.com \\ Cibele Antônia de Souza Rodrigues* \\ Secretaria de Educação do estado de Mato Grosso - Seduc/MT \\ E-mail: cibele.antonia@gmail.com \\ José Maria de Almeida Lara* \\ Secretaria de Educação do estado de Mato Grosso - Seduc/MT \\ E-mail: joselara.lara@yahoo.com.br \\ Jucelina Ferreira de Campos \\ Secretaria de Educação do estado de Mato Grosso - Seduc/MT \\ E-mail: jucelinaferreira@gmail.com
}

\section{Resumo}

Este artigo trata dos desdobramentos do Projeto: "Rádio e Teatro: da escrita à oralidade", realizado com alunos do Ensino Médio em 2014, na Escola Estadual Adalgisa de Barros, em Várzea Grande/MT. Tem por objetivo trazer à cena o encontro do teatro com a filosofia ocorrido no percurso desta experiência, na medida em que elaborou as fronteiras desses campos, permitindo aos jovens envolvidos desenvolver uma visão reflexiva e, consequentemente, uma postura crítica diante de suas realidades. Justifica-se na medida em que busca compreender e expor as possibilidades transformadoras do teatro, uma vez que ele promoveu questionamentos que abriram caminho para o encontro desses estudantes com seus anseios e dúvidas, o que possibilitou a eles transformarem, a priori, a si mesmos e a seu mundo, para, então, buscarem transformar o mundo a sua volta. Assim, tendo como base uma teatralidade filosófica, conclui-se que a escola tem um papel importante no desenvolvimento das potencialidades dos educandos, desde que ela oportunize, das mais variadas formas, experiências que possibilitem isso.

Palavras-chave

Teatro.Filosofia. Teatralidade filosófica.Escola.
Keywords

Theater. Philosophy. Philosophical theatricality. School.

\footnotetext{
* Aline Siqueira é doutora em Estudos de Cultura Contemporânea pela UFMT; Cibele Rodrigues é mestre em Estudos de Linguagem pela UFMT; José Lara é especialista em Interdisciplinaridade pelo Instituto Cuiabano de Educação; Jucelina de Campos é mestre em Estudos de Linguagem pela UFMT.
} 
Introdução

Todas as artes contribuem para a maior de todas as artes, a arte de viver. Bertolt Brecht

Este artigo apresenta os desdobramentos da primeira etapa do Projeto "Rádio e Teatro: da escrita à oralidade", realizado com alunos do Ensino Médio, em 2014, na Escola Estadual Adalgisa de Barros, em Várzea Grande/MT. $\mathrm{Na}$ tessitura deste, a escola é compreendida como um local privilegiado para o despertar filosófico do estudante, para a inserção social de jovens marginalizados, podendo o teatro representar um papel importante.

A respeito do tema que tratamos neste trabalho, "teatralidade filosófica", buscamos abordar o teatro tendo como baliza o Teatro do Oprimido, de Augusto Boal (1980), e a Pedagogia do Oprimido, de Paulo Freire (1987), também dialogando com Bertolt Brecht (1978) e Constantin Stanislaviski (1988). Para, então, articular essas teorias à educação a partir dos pensamentos de Moacir Gadotti (2013) e Celso Antunes (2013).

A reflexão fundamenta-se, ainda, nos conceitos da Folk comunicação (BELTRÃO, 1980), caracterizada pelo processo artesanal e horizontal, abrangendo três grandes grupos de audiência: os grupos rurais marginalizados, caracterizados sobretudo por seu isolamento geográfico, sua penúria econômica e baixo nível intelectual; os grupos urbanos marginalizados, compostos por indivíduos situados nos escalões inferiores da sociedade, constituindo as classes subalternas, desassistidas, subformadas e com mínimas condições de acesso e os grupos culturalmente marginalizados, urbanos ou rurais, que representam contingentes de contestação aos princípios, à moral ou à estrutura social vigente. Nesse sentido, os alunos do referido projeto, entendidos como sujeitos neste artigo, constituem a segunda categoria descrita.

Como a viabilização do Projeto "Rádio e Teatro: da escrita à oralidade" ocorreu devido ao repasse de recursos da primeira etapa do Programa "Mais Cultura nas Escolas", do Governo Federal (2014-2016), trataremos da legislação que regulamenta o ensino no Brasil, mais especificamente, as relacionadas ao teatro e à filosofia.

Inicialmente, explicitamos o aporte teórico que norteará a discussão. Em seguida, trilhamos os caminhos percorridos desde a elaboração até a implantação do projeto na escola, levando em conta as condições oferecidas pela escola para sua execução. Posteriormente, apresentamos os desdobramentos do projeto, materializados nas falas dos estudantes em um relatório sobre uma aula de campo realizada no Cine Teatro Cuiabá.

Por fim, tendo como aporte o que preconiza Deleuze (1988) acerca da teatralização do filosófico em Nietsche, tecemos algumas reflexões sobre os desdobramentos dessa experiência para os estudantes, a partir da análise dos depoimentos contidos nesses relatórios. Tendo em vista o exposto, buscamos trazer contribuições para uma reflexão sobre como a ressignificação da escola, através das atividades artístico-culturais-comunicacionais que podem promover a conscientização dos estudantes sobre si mesmos e, por consequência, do contexto social no qual estão inseridos. 
Abrem-se as cortinas: a história começa

O "Programa Mais Cultura nas Escolas" foi uma iniciativa do Governo Federal (2014-2016) que buscava incorporar a cultura como vetor de desenvolvimento, incluindo-a na Agenda Social - políticaestratégica de estado para reduzir a pobreza e a desigualdade social.

A nossa história com esse Programa teve início com a concepção da proposta elaborada para o Projeto "Rádio e Teatro na escola: da escrita à oralidade", o qual pretendia oferecer não somente oficinas de rádio e teatro na escola, como também possibilitar aos estudantes conhecer estes universos em suas várias dimensões, primeiramente como público, expectador, e, posteriormente, como integrantes e produtores dos mesmos.

Os eixos norteadores desse projeto eram a autonomia, a criatividade e o desenvolvimento da oralidade dos estudantes, buscando proporcionar aos sujeitos condições de desenvolver suas potencialidades, tornando o espaço escolar mais propício ao aprendizado, construindo caminhos alternativos para a construção dos saberes, por meio da oralidade e da ludicidade. Por isso mesmo, sendo também uma forma de estimular a interação entre as pessoas e facilitar a comunicação, pois como orientam os Parâmetros Curriculares Nacionais (PCNs) de Linguagens, "na vida social, e não somente na sala de aula, o aluno deve ser capaz de reconhecer como a linguagem foi organizada para produzir determinados efeitos de sentido" (BRASIL, 1999, p. 62).

Nesse sentido, nas palavras de Celso Antunes (2013, p.201), é essencial "ensinar o aluno a ver. Porque não é mesma coisa que olhar. Olhar é uma dotação da natureza biológica, o ser humano olha como os gatos, como os cães olham. Agora, ver é aprendizagem".

Assim, no ano de 2013, norteadas pelas exigências previstas nos documentos oficiais que regulamentam o ensino de Artes, as professoras idealizadoras do projeto, juntamente com a parceira Cultural, elaboraram o mesmo, com apoio da Articuladora de Projetos do ProEMle do então gestor da escola Prof ${ }^{a}$ Adalgisa de Barros, o que foi fundamental para escolha do projeto, em julho de 2014, pelo Ministério da Cultura (MinC), para integrar o Programa Mais Cultura nas Escolas.

$\mathrm{Na}$ fase inicial foram inscritos 48 alunos e 32 deles concluíram o curso. As oficinas eram realizadas em caráter extraclasse aos sábados à tarde, para possibilitar a participação de alunos dos três turnos de aula. A ideia, a priori, era apresentar a eles as técnicas básicas para se fazer um programa de rádio ou uma peça de Teatro. Contudo, os resultados foram muito além dos objetivos esperados, pois observamos um amadurecimento pessoal e cultural dos estudantes no decorrer das oficinas, lançando novos olhares para suas próprias realidades, o que nos instigou a aprofundar teoricamente os estudos e socializar academicamente todo o processo.

De acordo com a Lei n. 5.692/71, o ensino de Artes fazia parte da área, então, denominada Comunicação e Expressão, passando a integrar, com a adoção dos PCNs, a área de Linguagens, Códigos e suas Tecnologias. Os PCNs visam delinear as principais linhas de referência para a educação escolar, orientando a formulação das propostas curriculares das diversas regiões do Brasil, os projetos pedagógicos, as escolas e as ações dos docentes referentes à elaboração do planejamento didático. Quanto ao ensino de artes, o PCN do Ensino Médio observa que 
Por meio de prática sensíveis de produção e apreciação artísticas e de reflexões sobre as mesmas nas aulas de Arte, os alunos podem desenvolver saberes que os levam a compreender e envolver-se com decisões estéticas, apropriando-se, nessa área, de saberes culturais e contextualizados referentes ao conhecer e comunicar arte e seus códigos (BRASIL, 1999, p. 48).

Nessa perspectiva, as Orientações Curriculares para o Ensino Médio procuraram resguardar os avanços dos PCNs, garantindo, ao mesmo tempo, a inclusão de propostas reivindicadas por aqueles que lidam com o ensino da Arte, mas estabelecendo um contato mais estreito com os que se situam na ponta desse processo - os professores. O documento se propôs a tratar sobre as diversas manifestações da linguagem, e a arte, em específico, pois esta, numa visão atual, estabelece vínculos muito estreitos com o cotidiano e com todas as outras formas de saber, na medida em que permite a abordagem dos mais diversos aspectos da cultura ligados ao cotidiano, ao entretenimento, aos ofícios, às ciências, etc.

Nesse sentido, o Programa Ensino Médio Inovador (ProEMI) foi lançado pelo Governo Federal, em 2009, tendo por objetivo "garantir o acesso à educação de qualidade e atender as necessidades e expectativas dos jovens brasileiros" (BRASIL, 2013, p. 33). Sua proposta visa viabilizar a construção de um currículo interdisciplinar a partir dos Projetos de Redesenho Curricular (PRC) que deveriam "atender às reais necessidades das unidades escolares" e reconhecer "as especificidades regionais e as concepções curriculares implementadas pelas redes de ensino" (BRASIL, 2013, p.10).

A elaboração do PRC deveria ter como ponto de partida os macrocampos obrigatórios: Leitura e Letramento; Acompanhamento
Pedagógico e Iniciação Científica e Pesquisa. Como também os macrocampos optativos: Línguas Estrangeiras; Cultura Corporal; Produção e Fruição das Artes; Comunicação, Cultura Digital e uso de Mídias e Participação Estudantil. Sendo fundamental que as ações pensadas para cada macrocampo sejam elaboradas a partir das áreas de conhecimento e que envolvam "temáticas diversas por meio de diálogo entre os conteúdos dos diferentes componentes curriculares de uma ou mais áreas do conhecimento" (BRASIL, 2013, p. 14).

Esse documeto enfatiza a necessidade do trabalho interdisciplinar e a criação de macrocampos como estratégia para repensar o ensino de modo dinâmico, produtivo, atraente, de maneira interligada e inovadora e, por conseguinte, de melhor qualidade. Assim as ações nos campos que compõem cada macrocampos deverão ser estruturadas em práticas pedagógicas, sejam elas interdisciplinares ou multidisciplinares, a serem realizadas através de projetos. De forma a repensar a eleboração de um currículo que abarque todas as suas dimensões e ações de modo

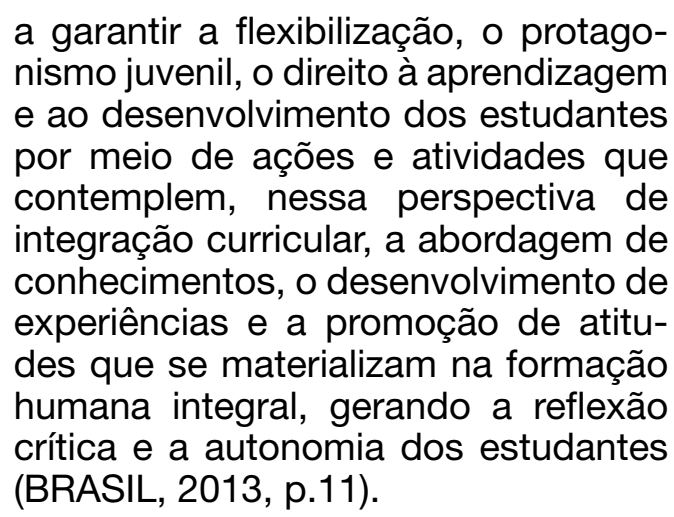

Nas palavras de Moacir Gadotti (2013, p.157) "as escolas são do tamanho do planeta", como também "um conjunto de relações sociais e humanas". Dentro do seu espaço físico circula esse conjunto de relações. Conside- 
rando isso, o autor afirma que, uma escola só existe se nela tiver projeto, é isso que a tornará importante. Ao afirmar isso, Gadotti corrobora com o pensamento de Fernando Hernández (1998), quando este autor enfatiza que projeto não é uma metodologia, mas uma forma de refletir sobre a escola e sua função, na medida em que a escola, a partir de ações mediadas por projetos, possibilite refletir suas práticas pedagógicas, a qual tenha como foco o desenvolvimento humano de forma integral, que permita gerar reflexão crítica e autônoma nos alunos, enquanto cidadão.

Nesse sentido, consideramos, também, fundamental para a elaboração do Projeto "Rádio e Teatro na escola: da escrita à oralidade", os macrocampos do PRC, em especial os optativos: Línguas Estrangeiras; Cultura Corporal; Produção e Fruição das Artes; Comunicação, Cultura Digital e uso de Mídias e Participação Estudantil.

Assim, o ensino de artes se fortaleceu, na medida em que o percurso histórico que $o$ consolidou proporcionou a inserção em seus domínios as linguagens da música, da dança, das artes visuais e do teatro, sendo a arte trabalhada de uma forma abrangente, interdisciplinar.

Para fins deste artigo, delimitamos a discussão ao teatro e seus desdobramentos na escola.

\section{A teoria em cena}

Augusto Boal, na condição de teatrólogo brasileiro, criador do Teatro do Oprimido (T.O.) apresenta na década de 70 uma proposta que visa não somente o conhecimento da realidade, mas, também, a transformação das nossas ações, da sociedade, na concepção de liberdade dos oprimidos, pois busca a ação dentro de si próprio e, assim a preparação para ações que estarão por vir.

Essa proposta teve ampla repercussão em muitos países, o que se dá, sobretudo, por ser uma metodologia de trabalho político, social e artístico. Seu alicerce está pautado na ideia de que todo o mundo é teatro e de que, de modo geral, todas as pessoas são atores, independentemente do fato de fazerem teatro ou não. Para Boal (1985, p. 17), a "alfabetização teatral é necessária porque é uma forma de comunicação muito poderosa e útil nas transformações sociais. Há que aprender a ler. Há que lutar pelos nossos direitos, há que utilizar todas as formas possíveis para promover a libertação".

O autor viveu e trabalhou em diferentes contextos que o levaram a utilizar o teatro como uma ferramenta, reinventando as suas técnicas e adaptando-o às necessidades das populações locais. Na América Latina, tratou dos problemas coletivos das comunidades, a maioria deles originados por sistemas políticos autoritários. Na Europa, adaptou essa ferramenta para trabalhar opressões individuais causadas por um estilo de vida moderno.

Para ele, o teatro, enquanto arte, é político e pode mostrar um mundo em transformação, possibilitando ensaiar uma revolução, sendo um instrumento para transformar a realidade social. Para o autor, "a arte modifica os modificadores da sociedade, transforma os transformadores. A sua ação é indireta, exerce-se sobre a consciência dos que vão atuar na vida real" (BOAL, 1985, p. 22).

Nos pressupostos teóricos do Teatro do Oprimido, de Boal (1985), e nos da Pedagogia do Oprimido, de Paulo Freire, observa-se uma 
intersecção de ideias, podendo-se observar um aspecto pedagógico para o teatro. E, seu projeto político se sobressai com intensidade se impondo por meio de um processo análogo ao que deu luz à pedagogia do Oprimido de Freire. Nesse sentido, ao afirmar que o teatro pode ser uma arma de libertação, de transformação social e educativa, Boal enfatiza a necessidade de transitividade do ensino, defendida por Freire. Assim, ambos reconhecem a importância de conscientização e da prática como forma de pôr fim à injustiça social, pois Práxis permite a transformação social (Freire, 2000), e T. O. gera práxis.

Nessa perspectiva, de acordo com Freire (1985), há pessoas que vivem numa cultura do silêncio, uma forma de opressão que as mantém à margem da sociedade e podem libertar-se por um processo de conscientização. $E$, essa conscientização implica em reflexão e prática sobre a realidade para se poder construir uma práxis libertadora. Esta surgirá pelo diálogo, a forma de traçar um caminho libertador e educativo (Freire, 2000). Portanto, "arte e estética são instrumentos de libertação" (BOAL, 2009, p. 19).

$E$, o teatro, nesse contexto, configura-se como um meio de se desenvolver essa postura reflexiva e crítica. Ainda que numa concepção epistemológica diferente desta, o filósofo francês Gilles Deleuze (1988) defende uma teatralização do filosófico, quando afirma que o pensamento Friedrich Nietzsche, é uma espécie de cena dramática, denominando de teatro da vontade de potência e do eterno retorno. Continua dizendo que o filósofo alemão teria conduzido pesquisas para a constituição de novos meios de expressão filosófica, tendo em suas obras um momento inaugural, primando pela presença da arte como um intercessor da filosofia, fazendo com que o discurso filosófico fosse pensado e praticado como um texto de invenção, como um escrito criativo, sujeito às características do estilo teatral.

Assim, o teatro e a cena dramática não estariam fora da proposta de irrigar o filosófico com a arte, tendo no teatro filosófico um possível e novo meio de expressão para a própria filosofia. Nesse sentido, o pensamento de Nietzsche seria privilegiado, pois ele,ao utilizar-se do teatro ao filosofar, fez mais que filosofia do teatro, ele criou novas possibilidades ao próprio filosofar ao experimentar novos meios de expressão filosófica, criando "na Filosofia, um incrível equivalente do teatro, fundando, desta maneira, este teatro do futuro e, ao mesmo tempo, uma nova Filosofia" (DELEUZE, 1988, p. 32).Assim, a arte, o teatro, pode colocar movimento na filosofia, sendo seu intercessor.

Nessa perspectiva,

O teatro passou a oferecer aos filósofos uma excelente oportunidade, aliás, aberta apenas a todos aqueles que desejavam não só explicar como também modificar o mundo. Fazia-se filosofia; ensinava-se, portanto (BRECHT, 1978, p. 48).

Tendo como baliza esses pressupostos teóricos para discussão sobre o teatro e a filosofia, pensamos ser necessário, antes de contextualizar o cenário das ações, discorrermos, de forma sucinta, sobre alguns pontos pertinentes em relação ao ensino de Artes e Filosofia.

No que se refere ao ensino de Artes, o PCN do Ensino Médio observa que:

Por meio de práticas sensíveis de produção e apreciação artísticas e de reflexões sobre as mesmas nas aulas de Arte, os alunos podem desenvolver saberes que os levam a compreender e envolver-se com decisões estéticas, 
apropriando-se, nessa área, de saberes culturais e contextualizados referentes ao conhecer e comunicar arte e seus códigos (BRASIL, 2000, p. 48).

Certamente existem muitas tentativas de se implementar as diretrizes dos PCNs em prática, a experiência aqui retratada é uma delas. É necessário lembrar que o que se propõe nos documentos oficiais, na maioria das vezes, permanece no campo da teoria. Embora haja, em certa medida, uma tentativa de modernizar as práticas escolares, elas ainda trazem muito dos resquícios do método tradicional de ensino, de origem tecnicista - baseado nos modelos taylorista e fordista da sociedade industrial do século XIX, que segundo Viviane Mosé (2013) chegou ao Brasil somente no século XX e se apresenta como

(...)uma educação fragmentada, dividida, sem contexto. [...] Por ser uma escola feita para as massas, nasceu não para se dedicar aos grandes temas da humanidade, mas para oferecer uma formação instrumental, voltada para o mercado; portanto trata-se de uma escola que não está voltada para o desenvolvimento humano, mas para o desenvolvimento da indústria (MOSÉ, 2013, p. 48-49).

Gadotti (2013) explica que o tecnicismo pedagógico se solidifica no Brasil, sobretudo no período mais autoritário de sua história, a ditadura militar, quando foram retiradas a filosofia, a sociologia e a arte do currículo desvencilhando "o currículo de qualquer vestimenta do pensar, qualquer vestimenta da reflexão" (GADOTTI, 2013, p. 130). Na tentativa de reduzir a informação ao útil, para o mercado de trabalho.

Essas ações tolheram o sistema educacional brasileiro, que permanece atrelado ao tec- nicismo e ao tradicionalismo, sem se dar conta de que a arte, da mesma maneira que a filosofia é essencial para a educação, uma vez que, possibilita a elaboração de raciocínios complexos que tornam as pessoas "potentes para transformar aquilo que os oprime" (MOSÉ, 2013, p. 52).

Desta forma, compreendemos que o ensino-aprendizagem faz-se como um processo contínuo, para além do espaço escolar, posto que, ao fazer sentido para a vida do estudante, tudo que ele concebe tomando como reflexão para sua vivência, para pensar e refletir sobre estar, e ser no mundo, ele amplia seus conhecimentos e ganha espaço e se reconhece em outros espaços se posicionando, como cidadão crítico, seja qual for o espaço em que ele se encontre.

Por isso, a importância de se relacionar o ensino de artes ao de filosofia, na medida em que, segundo os PCNs, pela sua especificidade, a Filosofia "abre o espaço por excelência para tematizar e explicitar os conceitos que permeiam todas as outras disciplinas, e o faz de forma radical", ou seja, buscando "suas raízes ou fundamentos e pressupostos", como também "discute os fins últimos da razão humana e os fins a que se orientam todas as formas de ação humanas, e sob esse aspecto, levanta a questão dos valores", além de não "tratar de um objeto específico, como nas ciências, porque nada escapa ao seu interesse, ocupando-se de tudo". Dessa forma, "a filosofia examina os problemas sob a perspectiva de conjunto - enquanto as ciências particulares abordam "recortes" da realidade - o que permite à Filosofia elaborar uma visão globalizante, interdisciplinar e mesmo transdisciplinar (metadisciplinar)" (BRASIL, 2002, p. 41).

Portanto, é necessário que o estudante 
seja estimulado de forma reflexiva, independentemente da disciplina, o que é defendido por Antunes (2013), ao afirmar que a filosofia é um instrumento extraordinário para pensar, contudo, também a matemática, a história, a biologia, ensinam a pensar, ou seja, todas as demais disciplinas, além da filosofia, também ensinam a pensar. Assim, nas palavras do autor, a filosofia deve estar presente na escola

Mais ou menos com aquela mesma significação que tem um extraordinário maestro diante dos seus músicos. Porque cada um dos músicos daquela orquestra tem a sua pauta e, portanto, sabe as notas que deve buscar, mas a regência, a coordenação, aquele sentido de harmonia, tem que ser dada por alguém. E é esse o grande papel da filosofia [...] (ANTUNES, 2013, p.213-214).

Dessa maneira, conforme orientam os documentos oficiais, o filósofo-educador, como é denominado o profissional da educação, tem como uma das funções, dar subsídios para o estudante analisar de maneira crítica a realidade e consiga "lançar outro olhar sobre o mundo e a transformar a experiência vivida numa experiência compreendida" (BRASIL, 2002, p. 42.).

Assim, não há como não reconhecera vocação da Filosofia para a percepção do todo. Sob essa ótica, há um desafio para o professor, de modo geral, ensinar a partir da interdisciplinaridade.

\section{O cenário}

Pensamos ser pertinente contextualizar o cenário de ação e seus sujeitos. A Escola Estadual Professora Adalgisa de Barros localiza-se na região central da cidade de Várzea Grande/ MT, por isso recebe uma grande diversidade de alunos oriundos de vários bairros, sendo cerca de 1.500 alunos. Atendendo apenas ao Ensino Médio, trabalha com três modalidades de ensino: Programa Ensino Médio Inovador (ProEMI) e Ensino Médio Integrado e a Educação Profissional (EMIEP), nos períodos matutino e vespertino e Ensino Médio por Semestralidade, no período noturno.

No ano de 2012, a escola foi inserida no ProEMI, programa que visava a melhoria do Ensino Médio público no Brasil, a partir da ampliação da carga horária letiva para mil horas anuais e do redesenho curricular, propondo um trabalho interdisciplinar a partir de projetos pedagógicos. Desde então, a escola vem buscando promover um redesenho curricular, pautando-se na legislação que regulamenta a organização do Ensino Médio.

Como a escola recebe estudantes de características muito diversificadas, os professores procuram adotar ações que possibilitem integrar os estudantes. De acordo com Gilberto Dimenstein (2007, p. 32), a periferia constitui um local de exclusão dos "benefícios sociais, culturais, tecnológicos e científicos", que não se baseia apenas em uma definição geográfica, mas, sobretudo, "de aspectos socioculturais e econômicos". Somado a isso, o município de Várzea-Grande, como um todo, possui características da rurbanidade, ou seja, se apresenta como "um escenario que combina prácticas, saberes, valores y objetos ruralesen contextos urbanos, modificando a laciudad"1 (KENBEL; CIMADEVILLA, 2009, p. 01). Tendo situado o contexto social dos sujeitos da expe-

1 Um cenário que combina práticas, conhecimentos, valores e objetos rurais em áreas urbanas, modificando a cidade (KENBEL; CIMADEVILLA, 2009, p. 01, tradução nossa). 
riência retratada neste artigo, podemos afirmar que a oferta do projeto em questão no espaço da escola se configurou como uma perspectiva de apreensão de bens culturais e, como desdobramento, de desenvolvimento de uma consciência filosófica.

\section{Mudança de cenário: novos olhares}

Além das aulas de conteúdos técnicos e teóricos, os sujeitos deste artigo tiveram a oportunidade de participar de duas aulas de campo, pois deve-se "procurar integrar espaços escolares com espaços culturais diversos, como equipamentos públicos de promoção à cultura, centros culturais, bibliotecas públicas, pontos de cultura, praças, parques, museus e cinemas" (BRASIL, 2014, p. 3).

A primeira atividade do projeto fora do espaço escolar foi uma Oficina de Improvisação Teatral, com o ator e diretor cuiabano André D'Lucca², no Cine Teatro Cuiabá. A oficina teve duração de oito horas, nas quais os alunos vivenciaram novas experiências a partir da prática da improvisação teatral, o que fez com que eles pudessem vislumbrar outras perspectivas de vida.

Como se observa no Relato ${ }^{3}{ }^{\circ} 9$, o contato com o teatro e a participação na oficina, concretizaram um sonho antigo do sujeito: "Fazer a oficina foi muito gratificante e marcante,

2 André D'Lucca é conhecido em Cuiabá por sua atuação no teatro, especialmente pela personagem Almerinda, da peça "Os Segredos de Almerinda". O ator cuiabano tem mais de 20 anos de história no teatro e já atuou em dezenas de peças em várias capitais do Brasil e da Europa. Tendo participado também de algumas novelas da Rede Globo de televisão.

3 Denominamos como "relato" as falas dos alunos retiradas do relatório solicitado, quando da participação destes na Oficina de Improvisação Teatral, citado na parte introdutória deste artigo. Como opção metodológica, numeramos essas falas para uma preservar as identidades. pude aprender várias coisas a cada instante e refletir que ali era um caminho certo para dar vida ao meu sonho que tenho desde criança de ser atriz, ou trabalhar no ramo de teatro".

A partir do que coloca Eduardo Marques (2007, p. 29), verificamos que um dos resultados de projetos como esse é "a redução da segregação social nesse espaço urbano que ainda é excluído", na medida em que "a ação política dos grupos da periferia, organizados politicamente ou não" podem transformar o estigma de exclusão que paira sobre os moradores dessa região.

Nessa perspectiva, pensando em ampliar ainda mais os horizontes dos alunos, pois percebemos o entusiasmo que se evidenciava em seus olhares contemplativos, propusemos, então, um passeio ao centro histórico da capital, no horário do almoço. Fomos ao Museu Histórico de Mato Grosso, onde os estudantes conheceram um pouco melhor capítulos importantes da história do estado de Mato Grosso; o Palácio da Instrução, que abriga a Biblioteca Estadual Rubens de Mendonça, a maior do Estado e a Galeria de Artes da Secretaria de Estado de Cultura, onde visitaram a exposição "Pantanal", de Wander Melo, artista plástico mato-grossense. Além do fazer teatral, no Cine Teatro Cuiabá eles tiveram contato com a arquitetura e a história do local.

E, como colocam Berselli e Isaacsson (2016, p. 24), alinhados ao pensamento de Stanislavisky, "contato é troca, troca entre atores, entre atores e espectadores, entre atores e o espaço, objetos, etc.". Neste processo de trocas, os jovens concederam entrevistas aos canais de comunicação que cobriam a programação oferecida pelo órgão. Isso propiciou a concretização de um dos objetivos do projeto, o protagonismo juvenil. Ou seja, ao ter contato 
com um mundo completamente novo e ainda poderem falar sobre suas experiências, os jovens passaram a perceber que fazem parte da sociedade, e mais, que são importantes para ela, ao ponto de serem ouvidos pela grande mídia, ou seja, a televisão.

O contato efetivamente se estabelece quando ambos nos colocamos em estado disponível para trocar com o outro, para realizar uma comunhão com o outro. Há aqui uma especificidade muito importante: ao estar em contato efetivo não há espaço para o fazer de conta, trata-se de um estado que depende da entrega e disponibilidade dos dois indivíduos que têm necessariamente de agir - reagir - no momento presente, tomando decisões, fazendo escolhas, colocando-se em estado de risco (BERSELLI; ISAACSSON, 2016, p.24).

Assim, "o contato seria uma possibilidade de abertura, de desnudamento, de disponibilidade a partir da qual emergiria o impulso de criação, por meio de uma relação profunda entre os atores" (BERSELLI; ISAACSSON, 2016, p. 25).

Isso pode ser evidenciado no entusiasmo que víamos nos olhares dos estudantes com a experiência de estar num palco "de verdade", o que nos remeteu ao pensamento de Augusto Boal (2000) sobre o olhar, para ele

[...] sempre foi esse o alicerce de todo espetáculo: dois atores se olhando. O olho é a parte mais vulnerável do corpo-humano! Por isso procuramos, recatados, esconder nossos olhos em momentos de emoção. Ou oferecê-los, em momentos de amor. Os atores devem-se oferecer seus olhares. É no olhar que se cria a estruturado espetáculo. É no olhar que nascem os personagens. É no olhar que se descobre a verdade. Não bastam olho aberto: falo do olhar profundo do qual até os cegos são capazes (BOAL, 2000, p. 142).
$\mathrm{E}$, vários relatos demonstram o quão significativas estas experiências foram, inclusive pelo fato de que, para alguns estudantes, era o primeiro contato direto com a arte elitizada, dos museus, galerias e teatros. Elas parecem ter despertado neles um maior prazer em descobrir o mundo do conhecimento, que se desvelou a partir destas vivências de ampliação cultural, pois, como afirma o psicanalista Jorge Broide,

A transformação deve ocorrer pela ver-
dadeira inclusão na cadeia simbólica,
o que pressupõe o trânsito das pesso-
as pela cidade, pela cultura, pelo me-
lhor que o ser humano produziu. Isso
subentende a possibilidade da circu-
lação da palavra, que se dá com base
na construção de uma tessitura no ter-
ritório, e do território para toda a cida-
de e para o mundo. É esse movimento
que gera escutas, cria matizes, dife-
renças, canais de comunicação, aber-
turas de pensamentos, outras formas
de trabalho e sobrevivência (BROIDE,
2007, p.31).

Esse pensamento é corroborado pelo Relato $n^{\circ} 5$, em que o sujeito demonstra a relevância desse tipo de experiências para a apreensão de conhecimento, colocando que
A oficina foi muito significante e im- portante, tanto para mim quanto meus colegas, todos nos divertimos muito, e melhor do que se divertir é se diver- tir com os amigos é poder fazer isso aprendendo novas coisas, novas téc- nicas. Creio que para muitos foi um dia inesquecível, como foi para mim. Penso que a cada mês deve-se ter au- las de campo, para ampliarem meus conhecimentos e de meus colegas, para obtermos mais noção das coisas, adquirir novos conhecimentos [...] que o mundo do teatro pode oferecer ( $\mathrm{Re}$ - lato $n^{\circ} 5$ ).

Na verdade, neste passeio, mas também ao longo do projeto, trabalhou-se para que não 
apenas a cultura elitizada fosse apropriada como sinônimo de cultura, para que justamente o contraponto dos dois mundos (centro e periferia) e o conhecimento de ambos os lados agissem na formação de novos pontos de vista sobre o tema. E, essa percepção pode ser observada neste e em outros relatos, uma vez que tiveram acesso a bens culturais para além do espaço escolar. Nesse contexto, segundo Gilberto Dimenstein (2007, p.32-33), quando "o jovem periférico tem a possibilidade de se integrar socialmente e ser um articulador comunitário e cultural, a periferia vira apenas um conceito geográfico e não mais um conceito socioeconômico e cultural".

Diante do exposto, ao estabelecer um diálogo entre saberes, valorizando a integração dos espaços escolares com equipamentos públicos, bem como, espaços culturais diversos, buscamos incluir os estudantes em ações importantes para a viabilização do protagonismo juvenil.

\section{— Novo enredo: teatralidade filosófica}

Explicado isso, trazemos à cena o pensamento de Jean-Jacques Roubine (2003), que nos guiou desde a fase inicial do projeto. Ele afirma que a representação não deve visar o realismo, ela se baseia não sobre o real, mas sobre o possível. Todavia, isso é delimitado, portanto, limitado, "pelo verossímil e pelo necessário" (ROUBINE, 2003, p. 15).

A partir dessa perspectiva, queríamos que os estudantes pensassem sobre as inúmeras possibilidades contidas no real, e não apenas reproduzissem as suas realidades. Tendo isso em mente, buscamos o envolvimento deles com os elementos referentes à estrutura cênica e dramática como figurinos, gestual e dicção dos atores, ação, espaço, personagem, público, etc., que, de acordo com Roubine (2003), englobam os inúmeros instrumentos que devem ser mobilizados para tornar o fingimento semelhante à própria verdade.

Nesse sentido, segundo Stanislavski (1988, p. 27), papel que não inclua uma verdadeira caracterização será pobre, falso para com a vida. Por isso, os atores devem lançar mão de caracterizações, não apenas" características exteriores, mas sim das interiores" (STANISLAVSKI, 1988, p. 26).

Para ele, geralmente, pensa-se que o diretor usa todos os recursos materiais para impressionar o público, quando na verdade, é o contrário. Os recursos são usados "mais em função do efeito que exercem sobre os atores", como "estímulos externos" calculados "para criar uma ilusão de vida real e da intensidade de seus estados de espírito" (STANISLAVSKI, 1988, p. 47).

Dessa forma, os elementos cênicos apresentam inúmeras possibilidades, ampliando o campo criativo, o que fez com que os estudantes familiarizassem mais facilmente com o ambiente teatral. Podemos verificar isso no Relato $\mathrm{n}^{\circ}$ 04, em que o estudante faz a seguinte colocação: "eu daria uma sugestão de levarem figurinos e objetos de teatro para nós, alunos, começarmos a nos adaptar mais rápido com isso".

Os relatos evidenciam, ainda que timidamente, o surgimento de uma nova postura, dentro de um cenário propício ao protagonismo juvenil. Sob outro prisma, isso também repercutiu em sala de aula e para além dela, como percebemos no Relato $n^{\circ}$ 8: "Foi um momento especial também, pois pudemos conhecer o Cine Teatro Cuiabá pela primeira vez. 
Sugiro que possamos fazer mais oficinas que trabalhem a oralidade e a interpretação. Como também visitas a museus, na UFMT, entre outros".

Opinião compartilhada pelo Relato $n^{\circ} 6$ : "Acredito que deva ter, pelo menos uma vez por mês, uma aula de campo, porque é uma boa oportunidade para nossa ampliação de conhecimento". E, também pelo Relato $\mathrm{n}^{\circ} 1$ : "Para minha escola, eu sugiro mais aulas de campos, nós podíamos [...] assistir algum espetáculo de teatro. Enfim o mundo do teatro e da rádio é muito vasto e é sempre bom conhecer mais e mais deles".

O "para além da escola" também significa a percepção de que o conhecimento pode se dar na interação com profissionais alheios ao ambiente escolar, como se observa no Relato $n^{\circ} 7$ : "A oficina foi muito legal, aprendi muito com ela (técnicas e expressão corporal), também fiquei muito grato de receber informações de outro profissional, além dos professores da oficina".

Isso também ficou evidenciado no Relato $n^{\circ}$ 8: "A oficina foi bem proveitosa, além da interação dos participantes com um ator experiente como o André D'Lucca, aprendemos algumas técnicas para improvisação e também dicas de posicionamentos com ator".

Os relatos ainda demonstram como esse tipo atividade possibilita um autoconhecimento, como o Relato $\mathrm{n}^{\circ}$ 3: "Foi maravilhoso ver a evolução de cada um ali, especialmente eu que cheguei lá toda tímida, não querendo nem me apresentar. E, a partir da $2^{\mathrm{a}}$ atividade, eu me soltei toda. Não queria nem mais parar de falar".

Como também no Relato $\mathrm{n}^{\circ} 4$ : "A oficina foi ótima, eu me senti com mais liberdade e me expressar porque no começo eu estava com muita vergonha e isso foi muito legal, foi uma sensação maravilhosa de estar lá". Já o aluno que faz o Relato $n^{\circ} 11$ acrescenta que além de se conhecer melhor, também pode interagir com o "outro": "Ao participar da oficina [...] meu objetivo era alcançar um meio de me expressar. E, estou conseguindo, como também a cada dia que passa ganho mais conhecimento e amigos novos".

Para Berselli e Isaacsson (2016), essa interação, na esfera do real, apresenta os seguintes mecanismos: toque, olhar, escuta; já o contato virtual é realizado por meio de trocas de energias, já os elementos de contato se referem ao objeto de contato, ou seja, com quem ou o que se entra em contato: pessoas, objetos, espaços. E, o contato transforma toda a ação em reação, num encontro nutrido pelas reações de ambos os lados, tendo o ator que "estar aberto a reagir a tudo o que o cerca, pode-se percebera necessidade de estar disponível ao contato" (BERSELLI; ISAACSSON, 2016, p. 33)

Esses relatos também dialogam com o famoso aforismo grego "conhece-te a ti mesmo"4, na medida em que podemos pensar esse autoconhecimento como ponto de partida para o desenvolvimento de um novo olhar diante do mundo, possibilitando enxergar outras formas de manifestações culturais, antes conhecidas, mas não vistas, pois segundo Stanislavski (1988, p. 78), o "ator deve ser observador não

4 "Conhece-te a ti mesmo" é um aforismo grego que revela a importância do autoconhecimento, sendo uma frase bastante conhecida no ramo Filosofia. Contudo, não se tem certeza sobre sua autoria, mas há vários autores que a atribuem ao sábio grego Tales de Mileto. Apesar disso, existem teorias que afirmam que a frase foi dita por Sócrates, Heráclito ou Pitágoras. O aforismo "Conhece-te a ti mesmo" está inscrito na entrada do templo de Delfos, construído em honra a Apolo, o deus grego do sol, da beleza e da harmonia. Em grego esta frase é gnōthiseauton. A frase completa é: "Conhece-te a ti mesmo e conhecerás os deuses e o universo." Disponível em: https://www.significados.com.br/conhece-te-a-ti-mesmo/ 
só quando está em cena, mas também na vida real. Deve concentrar-se, com todo o seu ser, em tudo o que chame sua atenção".

Isso pode ser observado no relato $n^{\circ} 11$ : "Antes, gostava de sertanejo e música eletrônica, mas com o passar das aulas, estou gostando de várias músicas diferentes. $\mathrm{E}$, vejo o mundo de outro jeito, mais compreensivo e vivo, observando como as pessoas andam, falam e se expressam de modo geral". Este relato demonstra a importância de ampliar "os saberes sobre produção, apreciação e história expressas em música, artes visuais, dança, teatro e também artes audiovisuais" (BRASIL, 1999, p. 172), gerando, dessa forma, sentidos outros a partir de novas vivências.

Cabe enfatizar que, quando nos conhecemos, conseguimos enxergar nossos limites, podendo superá-los, como exemplifica o Relato $n^{\circ}$ 9: "Realizei todas as atividades com um pouco de insegurança e vergonha, esse sempre foi um dos meus defeitos. Mas, também me senti confortável sabendo que ali tinham pessoas para aprender e ensinar. Naquele dia não está muito bem de saúde, estava gripada, mas queria me entregar por inteiro para aprender, dei o meu máximo mesmo não estando bem".

A diversidade de abordagens explicitadas nos relatos, demonstram, de forma concreta, a abrangência de conhecimentos possibilitada pelo contato com a arte. Nesse sentido, refletir sobre a aprendizagem nessa área implica pensá-la a partir de uma organização curricular interdisciplinar, que aproxime distintos referenciais teóricos e metodológicos que a compõem, buscando uma formação integral (BRASIL, 1999, p. 352).

\section{Considerações finais}

Inspirados pelos olhares curiosos dos estudantes e também pelos seus semblantes sedentos por "mais cultura", surgiu a necessidade de escrevermos sobre a experiência de participação neste projeto. Muitos enfrentamentos ocorreram, desde o momento da tessitura do projeto, em 2013, até este artigo. Contudo, os relatos demonstram que valeu a pena, pois vimos, de forma ainda tímida, o desvelamento para os estudantes de um universo de possibilidades de conhecimento para além da escola. $E$, talvez, em algum momento ou em algum lugar de suas jornadas, eles sejam convocados a explorar a curiosidade típica dos artistas mais inquietos e quem sabe não resistam a assistir a uma peça de teatro, visitar uma exposição, dar uma entrevista, escrever um projeto para sua comunidade, ou qualquer outra tomada de iniciativa nas quais sejam protagonistas.

Isso também repercutiu em nós, pois nos fez pensar em nosso papel enquanto educadores. Nessa perspectiva, "arte modifica os modificadores da sociedade, transforma os transformadores. A sua ação é indireta, exerce-se sobre a consciência dos que vão atuar na vida real" (BOAL, 1985, p. 22).

Por isso, cabe aqui ressaltar que, em 2016, em uma atividade sobre gêneros textuais na aula de Língua Portuguesa, um dos participantes do Projeto "Rádio e Teatro: da escrita à oralidade" elaborou um projeto para organizar um Festival de Teatro na Escola, o qual não pode ser viabilizado. Mas, esta iniciativa de mostra que aquele projeto, do Programa Mais Cultura, reverberou e teve desdobramentos, na medida em que o mesmo estudante insistiu e conseguiu mobilizar colegas e as professoras en- 
volvidas no citado projeto de 2014ainscrever a escola para participar, pela primeira vez, do $13^{\circ}$ FETRAN (Festival Estudantil Temático de Trânsito).

E, mesmo a escola entrando em greve, prosseguimos com as atividades para nossa apresentação em uma das etapas regionais do Festival, sob a direção da então Coordenadora Pedagógica. Também teve importante papel nessa participação um grande profissional da área teatral, com vasta experiência no ramo que, naquela ocasião, cursava Artes Visuais e estagiava na escola.

A peça apresentada pela escola conseguiu o vice-campeonato da Etapa Cuiabás, na Categoria Juvenil. Porém, o mais gratificante foi o reconhecimento, com o prêmio de ator destaque $^{6}$, do estudante que primeiro acreditou ser possível tal participação.

Por isso, acreditamos que o teatro seja um dos elementos que podem fazer com que uma mente que se abriu para novas experiências, nunca mais volte ao seu tamanho original, pois "consciência é a reflexão do sujeito sobre si próprio e sobre o significado dos seus atos" e"pensar é organizar o conhecimento e transformá-lo em ação" (BOAL, 2009, p. 29-30).

Contudo, este procedimento implica, para qualquer que seja a área de conhecimento estudada, um processo de ensino-aprendizagem que não seja aquele restrito ao espaço escolar, pois o conhecimento precisa ser vivenciado e relacionado com a prática, para que os sujeitos envolvidos se sintam produtores de seus próprios saberes. Nesse contexto, foi possível notar que eles estão avançando (cada um a seu tempo e seu modo) na construção de uma postura crítica, que entende a cultura, como uma diversidade de práticas sociais.

E, a partir desta nova perspectiva, eles poderão se ver e se ressignificar enquanto cidadãos críticos na sua prática, podendo mudar a realidade na qual estão inseridos. Nesse sentido, segundo Augusto Boal (2009), quem transforma as palavras em versos se torna um poeta, quem transforma o barro em estátua se torna um escultor $\mathrm{e}$, ao transformar as relações sociais e humanas apresentadas em uma cena de teatro, torna-se um cidadão.

Assim, traçando um quadro comparativo entre a Pedagogia e o Teatro do Oprimido, a educação se apresenta "como um processo que extravasa a escola e segue pela vida, em sua transformação - vocação humana de ser mais" e o espetáculo "como um processo que extravasa o teatro e segue pela vida, exigindo ações concretas em transformação da realidade" (PARANHOS, 2009, p.99).

Nesse sentido, iniciativas que permitam o acesso a diversos benefícios culturais, contribuem muito para a formação crítica dos nossos estudantes. Isso pode potencializar as competências adormecidas em cada um deles, pois mesmo que essas vozes, que ecoaram e ressoaram, possam apresentar resultados ainda tímidos, observamos que há muitos caminhos para dar continuidade ao que foi instigado em nossos alunos.

5 http://www.varzeagrande.mt.gov.br/conteudo/15896

6 http://www.varzeagrande.mt.gov.br/imagem/45463 


\section{Referências}

ANTUNES, Celso. Celso Antunes e formação do professor: é preciso muito mais o que conteúdo. Entrevistado por Viviane Mosé In: A escola e os desafios contemporâneos. Organização e apresentação, Viviane Mosé. $1^{a}$ ed. Rio de Janeiro: Civilização Brasileira, 2013, pp. 213, 214.

ASSOCIAÇÃO BRASILEIRA DE NORMAS TÉCNICAS.NBR 10520: informação e documentação- apresentação de citações em documentos. Rio de Janeiro, 2002.

BELTRÃO, Luiz. Folkcomunicação: a comunicação dos marginalizados. São Paulo: Cortez, 1980.

BENDELAK, Olivar. Teatro legislativo: Exercício pleno da cidadania. 2009. Disponível em http://ctorio.org.br/novosite/wp-content/uploads/a2p.cache.teatro-legislativo.pdf. Acessado $23 / 06 / 2017$.

BENJAMIM, Roberto. Folkcomunicação: da proposta de Luiz Beltrão à contemporaneidade.2011. Disponível em http://www.eca.usp. br/associa/alaic/revista/r8-9/ccientifica 06.pdf Acessado em 13/05/2015.

BERSELLI, Marcia; ISAACSSON, Marta. O contato no processo de criação do ator: considerações a partir de relações entre Stanislavski, Grotowski e Boal e o contato improvisação. Cena, n. 21, p. 22-36. Disponível em http://seer.ufrgs.br/index.php/cena/article/ view/67501. Acessado em 04/06/2017.
BIÃO, Armindo Jorge. Metáfora teatral e a arte de viver em Sociedade. Caderno $\mathrm{CRH}, \mathrm{n} .15$, p. 104-110, Jul./dez., Disponível em http:// www.repositorio.ufba.br:8080/ri/bitstream/ ri/2098/1/CadCRH-2007-376.pdf. Acessado em 20/06/2017.

BOAL, Augusto. 200 exercícios e jogos para o ator e o não-ator com vontade de dizer algo através do teatro. $6^{\mathrm{a}}$ ed. Rio de Janeiro: Civilização Brasileira, 1985.

. A estética do oprimido. Rio de Janeiro: Garamond, 2009.

. Hamlet e o filho do padeiro: memórias imaginadas. Rio de Janeiro: Record,2000.

. Teatro do Oprimido e Outras Poéticas Políticas. $4^{a}$ ed. Rio de Janeiro: Civilização Brasileira, 1980.

BRASIL. MINISTÈRIO DA EDUCAÇÃO. SECRETARIA DE EDUCAÇÃO BÁSICA. Orientações Curriculares para o Ensino Médio: Linguagens, códigos e suas tecnologias. Ministério da Educação. Secretaria de Educação Básica: Brasília (DF), 2006 v.l; il.

BRASIL. MINISTÈRIO DA EDUCAÇÃO. SECRETARIA DE EDUCAÇÃO MÉDIA E TECNOLÓGICA. Parâmetros Curriculares Nacionais: Ensino Médio. Ministério da Educação. Secretaria de Educação Média e Tecnológica: Brasília (DF), 1999; il. 
BRASIL. MINISTÉRIO DA EDUCAÇÃO. SECRETARIA DE EDUCAÇÃO BÁSICA. Programa Ensino Médio Inovador: Documento orientador. Ministério da Educação. Secretaria de Educação Básica: Brasília (DF), 2013.

BRASIL. MINISTÉRIO DA EDUCAÇÃO. FUNDO NACIONAL DE DESENVOLVIMENTO DA EDUCAÇÃO. MINISTÉRIO DA EDUCAÇÃO. Resolução/FNDE $n^{\circ} 4$ de 31 de março de 2014. Disponível em http://www.educacao. ma.gov.br/Documentos/resolucao n4 de 3103-2014 mais\%20cultura.pdf. Acessado em 13/08/2015.

BRASIL. MINISTÈRIO DA EDUCAÇÃO. SECRETARIA DE EDUCAÇÃO BÁSICA. Orientações Curriculares para o Ensino Médio: Ciências Humanas e suas tecnologias. / Secretaria de Educação Média e Tecnológica - Brasília : MEC ; SEMTEC. 2002.

BRECHT, Bertolt. Estudos sobre teatro. Rio de Janeiro: Nova Fronteira,1978.

BROIDE, Jorge. Espaços em transformação: depoimento [junho/julho, 2010]. São Paulo: Revista Continuum. Entrevista concedida a Mariana Sgarioni e Rafael Tonon.

CANDA, Cilene Nascimento. Paulo Freire e Augusto Boal: Diálogos entre educação e teatro. HOLOS, v. 4, 2012. Disponível em http://www. redalyc.org/html/4815/481549278015/>> Acessado 05/06/2017.

DELEUZE, Gilles. Diferença e Repetição. Rio de Janeiro: Graal, 1988.
DELEUZE, Gilles. O Ato de Criação. Palestra de 1987. Edição brasileira: Folha de São Paulo, 27/06/1999. Tradução José Marcos Macedo.

DIMENSTEIN, Gilberto. Espaços em transformação: depoimento [junho/julho, 2010]. São Paulo: Revista Continuum. Entrevista concedida a Mariana Sgarioni e Rafael Tonon.

FREIRE, Paulo. Pedagogia da indignação: cartas pedagógicas e outros escritos. São Paulo. Editora UNESP, 2004.

. Pedagogia do oprimido. Rio de Janeiro: Paz e Terra, v. 3, 1987.

GADOTTI, Moacir. Moacir Gadotti e a escola cidadã. Entrevistado por Viviane Mosé In: A escola e os desafios contemporâneos. Organização e apresentação, Viviane Mosé. $1^{a}$ ed. Rio de Janeiro: Civilização Brasileira, 2013.

HERNÁNDEZ, Fernando. Transgressão e Mudança na Educação. POA: Artmed. 1998.

KENBEL, Claudia; CIMADEVILLA, Gustavo. La rurbanidad desde el enfoque de las memorias sociales. X Jornadas Argentinas de Estudios de Población, 2009.

MARQUES, Eduardo. Espaços em transformação: depoimento [junho/julho, 2010]. São Paulo: Revista Continuum. Entrevista concedida a Mariana Sgarioni e Rafael Tonon. 
MARTINS, Vânia; LUCIO-VILLEGAS, Emilio. Teatro do oprimido como ferramenta de inclusão social no bairro Horta da Areia em Faro. Sociologia, p. 57-75, 2014. Disponível em https://idus.us.es/xmlui/bitstream/handle/11441/30361/Articulo FLUP.pdf?sequen$\underline{c e=1 \& i s A l l o w e d=y}$. Acessado em 10/06/2017.

MATO GROSSO. SECRETARIA DE ESTADO DE EDUCAÇÃO. Orientações Curriculares: Área de Linguagens: Educação Básica. Secretaria de Estado e Educação de Mato Grosso: Cuiabá: 2012.

MOSÉ, Viviane. A escola e os desafios contemporâneos. Organização e apresentação. $1^{\text {a }}$ ed. Rio de Janeiro: Civilização Brasileira, 2013.

PARANHOS, EDMUR. Nós: Do discentes e espect-atores. 2009. Tese de Doutorado. Dissertação de Mestrado não publicada). Universidade Federal do Rio de Janeiro, Rio de Janeiro, Brasil. Disponível em http://www. educacao. ufrj. br/ppge/dissertacoes/dissertacao edmur nelson nogueira paranhos junior.pdf. Acessado em 05/06/2017

ROUBINE, Jean-Jacques. Introdução às grandes teorias do teatro. Rio de Janeiro: Jorge Zahar Ed. 2003.

STANISLAVSKI, Constantin. Manual do Ator. São Paulo: Martins Fontes, 1988
TEIXEIRA, Tânia Márcia Baraúna. Dimensões Sócio Educativas do Teatro do Oprimido de Augusto Boal. Disponível em http://www.iacat. com/revista/recrearte/recrearte04/Seccion4/ Teatro\%20del\%20oprimido.pdf. Acessado em 19/06/2017.

VASCONCELLOS, JLR. O pensamento e a cena: Teatro e Filosofia em Gilles Deleuze. Aisthe, v. 3, p. 87-95, 2008. Disponível em http:// aisthe.ifcs.ufrj.br/vol\%20II/JORGE.pdf. Acessado em 05/06/2017.

Recebido: 23/06/2017

Aprovado: 04/02/2018 